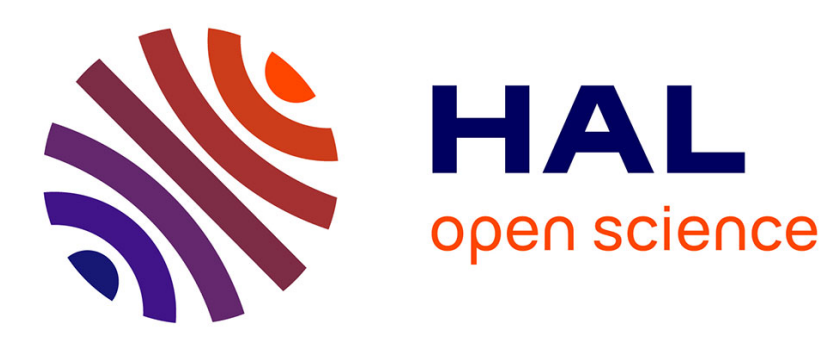

\title{
Open crack depth sizing by multi-speed continuous laser stimulated lock-in thermography
}

\author{
Christine Boué, S Holé
}

\section{To cite this version:}

Christine Boué, S Holé. Open crack depth sizing by multi-speed continuous laser stimulated lock-in thermography. Measurement Science and Technology, 2017, 28, pp.065901 10.1088/13616501/aa687b . hal-01522799

\section{HAL Id: hal-01522799 \\ https://hal.sorbonne-universite.fr/hal-01522799}

Submitted on 15 May 2017

HAL is a multi-disciplinary open access archive for the deposit and dissemination of scientific research documents, whether they are published or not. The documents may come from teaching and research institutions in France or abroad, or from public or private research centers.
L'archive ouverte pluridisciplinaire HAL, est destinée au dépôt et à la diffusion de documents scientifiques de niveau recherche, publiés ou non, émanant des établissements d'enseignement et de recherche français ou étrangers, des laboratoires publics ou privés. 
Open crack depth sizing by multi-speed continuous laser stimulated lock-in thermography

C. Boué, S. Holé

Sorbonne Universités, UPMC Univ Paris 06, F-75005 Paris, France

LPEM, CNRS, ESPCI Paris, PSL Research University, 10 rue Vauquelin, F-75005 Paris, France

corresponding author: christine.boue@espci.fr

\section{Abstract}

A crack located in the thermal diffusion zone of a heat source behaves like a thermal barrier modifying the heat diffusion. For a moving continuous source, the sample surface is heated on a little area near the crack for a duration which depends on the speed of the thermal source. A lock-in process synchronized by the displacement of the continuous heat source along the crack is studied. The thermal signature of the crack is extracted via a space operator applied to the amplitude and the phase of surface temperature images for various speeds of the thermal source. With the technical solution presented in this article, the thermal signature images are analysed according to a length representative of the thermal diffusion length to give a local evaluation of the crack depth (around $3 \mathrm{~mm}$ at the maximum) for crack lengths of about few centimetres long. The multi-speed lock-in thermography approach is initially studied with Finite Element Method (FEM) simulations. Experimental tests using an infra-red camera validate the method in a second part. The results do not depend on the heating source if its power is sufficient to produce a temperature rise detectable by an infra-red camera. The depth estimations are obtained independently of the crack width and heat source trajectory. The multispeed lock-in thermography is a method without contact, without sample preparation, non-polluting, non-destructive and with simple optical adjustments.

Key Words: Infrared thermography, lock-in thermography, non-destructive testing, crack depth, crack sizing, continuous laser heating

\section{Introduction}

Cracks in metals caused by fatigue or creep grow predominantly perpendicular to the material surface. Crack depth evaluation in these metals is a major milestone in industry (nuclear, aerospace...) to assess 
danger risks and thus to prevent structure damages. The active infrared thermography is a non-contact and non-destructive promising technique for perpendicular crack detection. It uses a local heating solicitation which can be continuous [1-3], pulsed [4-8] or modulated [9-10]. The disturbances of the heat diffusion produced by a crack which acts as a thermal barrier are then analyzed. But these disturbances depend also on parameters like the surface state of the sample, the crack width and the spatial configuration of the heating excitation [2,6,8,9,11-14]. Consequently, the evaluation of the crack depth is difficult to extract and modelling is often required to obtain reliable information [15-17].

The multi-frequency lock-in infrared thermography method [18-22] is a local method to evaluate perpendicular crack depths independently of their width, that needs no surface preparation and no calibration procedure. The spatial second derivative (Laplacian) of both amplitude and phase infrared images acquired at the heating frequency are analyzed as a function of the thermal diffusion length to deduce a local depth indicator (on a few pixel) [18]. Good results are obtained with this method but around 5 minutes are necessary for one local measurement within the range of a few millimetre.

The aim of this paper is to describe a method for scanning a crack of a few centimetre long and to evaluate its depth along its whole length. This new proposed idea is to use the absorption of a continuous heating source moving at different speeds $v_{i}$ to probe inside the sample. A lock-in detection system is synchronized with the movement of the heating source. This new approach exploits the evolution of crack thermal footprint at different scanning speeds.

In the first part of this article, 3D Finite Element Method (FEM) numerical simulations from COMSOL Multiphysics [23] are used to introduce a depth indicator which relies on the evolution of the first spatial derivative of both amplitude and phase images as a function of a pseudo thermal diffusion length. In the second part of this article, the implementation of the new approach is presented to evaluate linear surface open cracks from measurements with an infra-red camera. Experimental results are obtained with controlled "cracks" in steel blocks as well as an induced fatigue crack.

\section{Multi-speed lock-in thermography method}




\subsection{Principle of the method}

The sample is heated by a moving continuous heat source of radius $r$. The heating source moves parallel to the crack on a distance $L$ at a speed $v$. Then the heating source is switched off to return back to its initial position as quickly as possible. Each heated point sees the thermal source during approximately $\Delta \tau 2 r / v$ which can be compared to the duration $\Delta t=L / v$.

For low moving speeds $v$, the heat diffuses on a larger distance than for high speeds. In comparison with a modulated configuration, we propose a pseudo thermal diffusion length $\mu^{*}$ defined as:

$$
\mu^{*}=\sqrt{\frac{\alpha L}{\pi v}}=\sqrt{\frac{\alpha \Delta t}{\pi}}
$$

where $\alpha$ is the thermal diffusivity of the material. The pseudo thermal diffusion length $\mu^{*}$ can be adjusted as required by varying the speed $v$. For $v$ such that $\mu^{*}$ is smaller than the distance $d$ between the heat source and the crack edge, the varying part of the heat flux reaching the crack before vanishing is very small. In the special case where the diffusion length is of the order of the distance to the crack, the heat flux reaches the edge of the crack on the surface and then is blocked. For longer diffusion lengths, the heat flux diffuses deeper into the volume along the crack and may bypass the defect, being then less blocked. All these behaviors can be detected from surface temperature measurements.

The evolution of the surface temperature is analysed by Fast Fourier Transform (FFT) in synchronism with the heat source displacement. A signal corresponds to the evolution of the surface temperature at one position. Therefore, there are as much signals as studied points on the sample surface. For a classical modulated fixed source, a FFT processing of the signals can be used to retrieve both amplitude and phase at the fundamental frequency. For a moving continuous heat source at speed $v$, the frequency of interest in the FFT processing of the signals acquired during one scan when the heat source in $\mathrm{ON}$ is equal to $1 / \Delta t=v / L$. The amplitude and phase signals of the sequences obtained 
for each speed are thus calculated by FFT at frequencies $f_{i}=v_{i} / L$. A dedicated analysis is then applied to finally retrieve the open crack depth.

\subsection{Simulation configuration}

A 3D heat flow simulation model has been developed with COMSOL Multiphysics 4.3 software in order to describe and analyze the interactions between a moving hot spot and a crack of known geometry.

This model considers a metallic block with an open linear crack perpendicular to the surface of length $L$, width $w(w<<L)$ and with a constant or non constant depth $h(x)$ along the $x$ direction. The local thermal excitation of the surface of the metallic specimen is considered homogeneous and circular, with a radius $r$. The center of the heating spot is located at a distance $d(x)$ from the crack (Figure 1).

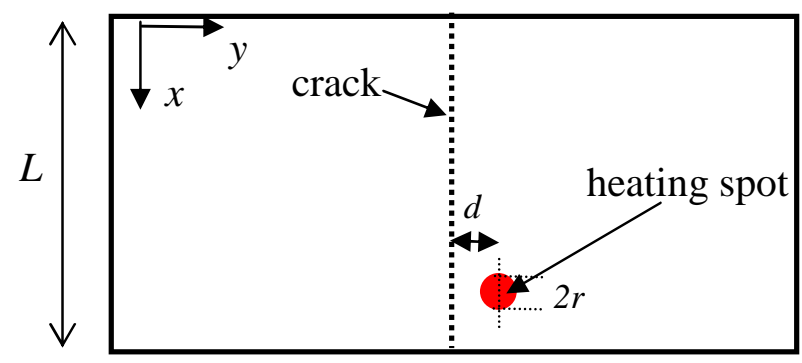

Figure 1: $x, y$ surface sample model.

In the absence of internal heat source, the 3D heat transfer equation in solids can be written as:

$$
\text { p.c. } \frac{\partial T}{\partial t}-\nabla \cdot(k . \nabla T)=0,
$$

where $\rho$ is the mass density, $c$ the specific heat, $k$ the thermal conductivity, $T$ the temperature and $t$ is time and $\nabla$ the gradient operator [24].

In the model, the influence of radiative and convective heat transfers is neglected. The boundary conditions for the heat flux can be written in the following form:

$$
k . \nabla T=\Phi(x, y)
$$


where $\Phi(x, y)$ is the term which describes the heat flux transfer at positions $(x, y)$. As a consequence, $\Phi(x, y)$ is different from zero only at portions $\mathrm{P}$ corresponding to the laser spot, assuming an illuminated circular surface of area $S=\pi r^{2}$. Across the lateral sides, the insulated boundary conditions are assumed $(k . \nabla T=0)$.

Equations (2) and (3) can be used to calculate the temperature of the thermally excited surface. The initial value of the temperature is the room temperature $\left(T_{0}=293 \mathrm{~K}\right)$ in the whole domains.

The heat source moves along the whole length $L$ at different speeds $v_{i}$. The OFF duration is proportional to the $\mathrm{ON}$ duration (e.g. $5 \%$ or $10 \%)$. In order to optimally characterize the defect on the investigated structure, the crack should be located inside the heat diffusion region, within a distance $d$ from the source of the order of the pseudo thermal diffusion length defined in Equation (1).

\subsection{Implementation of the finite element modeling}

The geometrical parameters of the cracks used in FEM simulations are shown in Table 1.

Table 1. Simulation parameters

\begin{tabular}{|c|c|c|c|}
\hline Thermal parameters of the metallic block & $\mathrm{k}=12.4 \mathrm{~W} \mathrm{~m}^{-1} \mathrm{~K}^{-1}$ & $\mathrm{c}=446 \mathrm{~J} \mathrm{~kg}^{-1} \mathrm{~K}^{-1}$ & $\rho=8430 \mathrm{~kg} \mathrm{~m}^{-3}$ \\
\hline Dimensions of the specimen $(\mathrm{mm})$ & length $=20$ & width $=15$ & height $=10$ \\
\hline Dimensions of the crack $(\mathrm{mm})$ & $L=20$ & $w=4010^{-3}$ & $h=0$ to 3 \\
\hline Distance laser spot to crack $(\mathrm{mm})$ & & $d=1.25$ \\
\hline Laser beam radius $(\mathrm{mm})$ & $r=0.25$ \\
\hline Laser beam power $(W)$ & 2 \\
\hline Heat surface absorption & \multicolumn{3}{|c|}{$0.5,1,1.4,2.5,5$} \\
\hline ON/OFF cycle durations $(s)$ & \multicolumn{3}{|c|}{200} \\
\hline Spot displacement increment $(\mu \mathrm{m})$ & \multicolumn{3}{|c|}{} \\
\hline
\end{tabular}

A tetrahedral meshing is adapted to the various domains of the sample (bulk or vicinity of the crack). The number of mesh elements is about 200 000. A mesh example is shown in Figure 2. At the top of the surface, a finer meshing is used in order to access to temperature variations with a sufficient spatial resolution. 


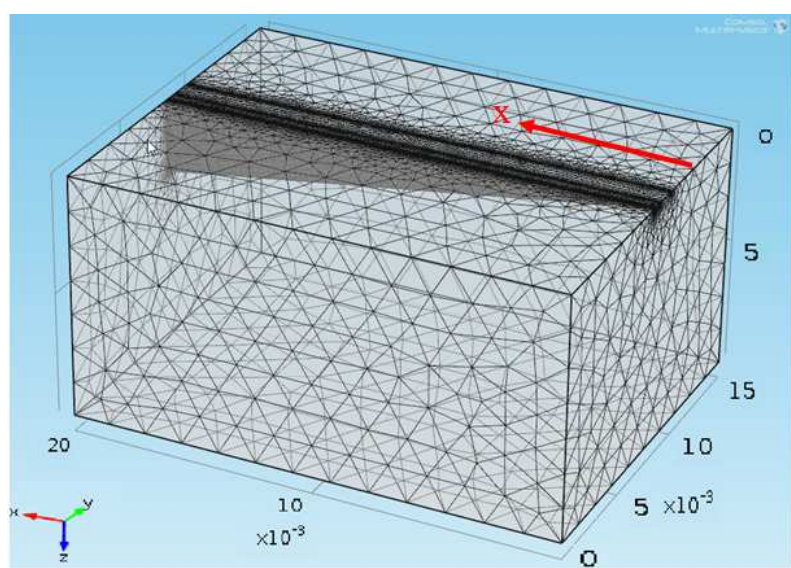

Figure 2: Typical mesh for FEM simulations for a non constant crack depth $h(x)$. The mesh contains 263000 elements.

150 surface temperature images are calculated by COMSOL during one ON/OFF cycle: 142 images during $\mathrm{T}_{\mathrm{ON}}, 8$ images during $\mathrm{T}_{\mathrm{OFF}}$. Thus, the heat source moves in $x$ direction by steps of around $200 \mu \mathrm{m}$ with successively 5 speeds. Figure 3 shows the position (a) and the state (b) of the heating spot as a function of time for the 5 ON/OFF cycles.

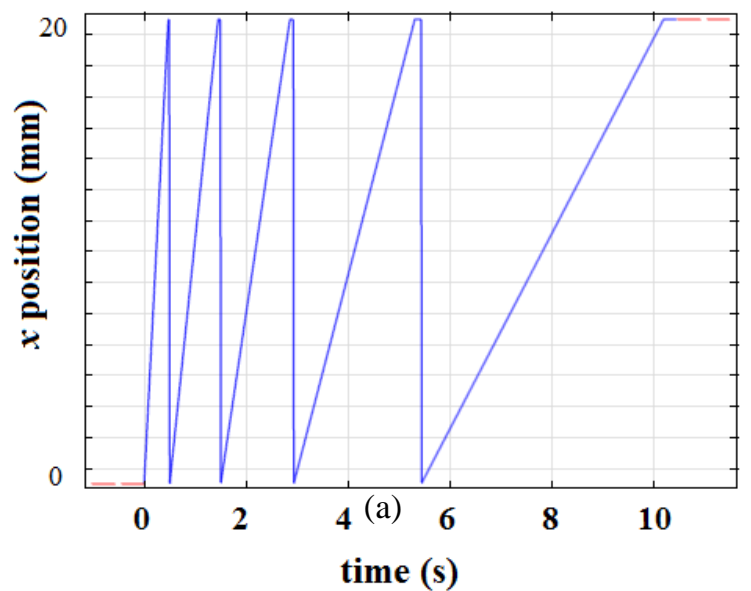

(a)

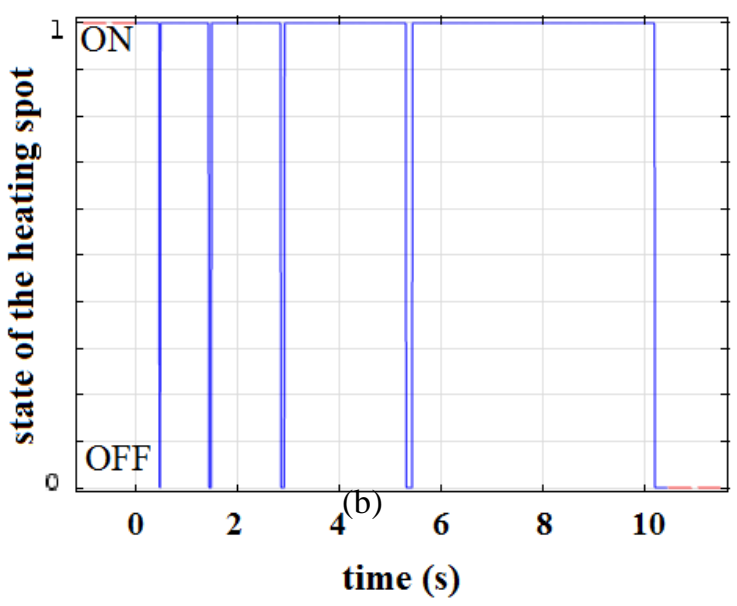

(b)

Figure 3: 5 different ON/OFF cycle durations ( $0.5 \mathrm{~s}, 1 \mathrm{~s}, 1.4 \mathrm{~s}, 2.5 \mathrm{~s}, 5 \mathrm{~s})$. (a) x displacement of the heating spot. (b) state of the heating source (ON/OFF). OFF duration is $5 \%$ of $\mathrm{ON}$ duration.

Typical temperature evolutions obtained during the heating profile of Figure 3 are presented in Figure 4 for 2 different pixels near the crack. 


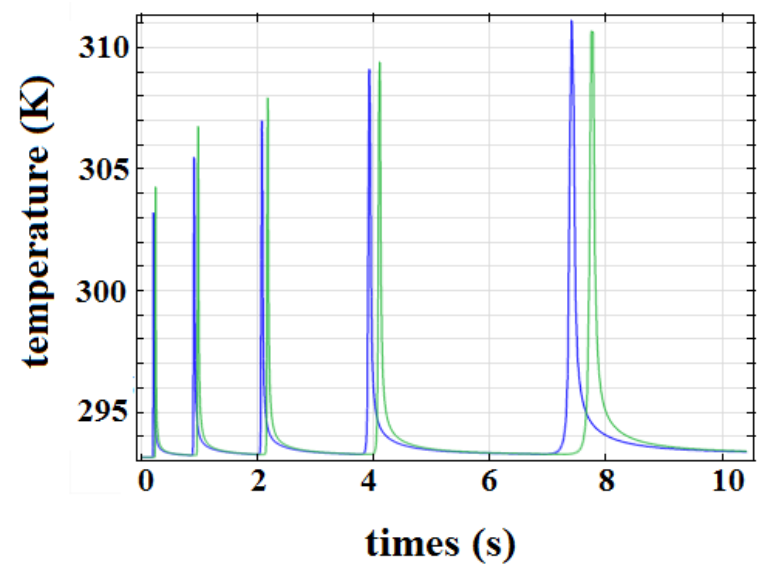

Figure 4: Temperature evolution of 2 pixels near the crack during the 5 cycles described in Figure 3.

These profiles are afterward analysed to extract the local depth of the crack.

\subsection{Data analysis procedure}

To avoid using excessively large files, the resulting simulated surface temperature images are resampled in space by using a square grid with a $70 \mu \mathrm{m} \times 70 \mu \mathrm{m}$ pixel size and in time by taking 50 images per displacement. The thermal data are then analyzed by applying an image processing FFT algorithm to each series of images. Consequently, the calculated amplitude and phase images are obtained at frequency $f=1 / \Delta t$. Figure 5 shows an example of amplitude (Figure $5 \mathrm{a}$ ) and phase (Figure $5 b)$ images of $300 \times 200$ pixels obtained at $f=0.2 \mathrm{~Hz}$. The linear crack footprint is clearly visible in the Figures 5 at the left of the heat source. For using the phase (Figure $5 b$ ) in the calculation, it is necessary to correct it from the shift introduced by the heating spot displacement. For that purpose, the phase is corrected with a linear adjustment: each pixel phase on a line along $y$ axis is shifted so that the spot phase of the studied line is equal to $360^{\circ}$. The result is presented in Figure 6a.

In previous work [18], the absolute value of the Laplacian of the amplitude image function and the gradient of the phase image were used to extract the crack responses. In this work, it is chosen to multiply the amplitude image $A$ with the phase image $\varphi$ to emphasize the crack signals before to extract it with a spatial operator (gradient or Laplacian). The resulting image of $A . \varphi$ for $f=0.2 \mathrm{~Hz}$ is shown in Figure 6b. A set of pixels $P(x, y)$ located on the crack which faces the heating zone are extracted from the gradient $\mathrm{G}$ of the image $A . \varphi$ with a basic numerical processing described in [25]. 
The values $G(x, y)$ of the selected pixels $P(x, y)$ shown in Figure 6c depend on the crack geometry, the heating area and the speed of the heating spot.

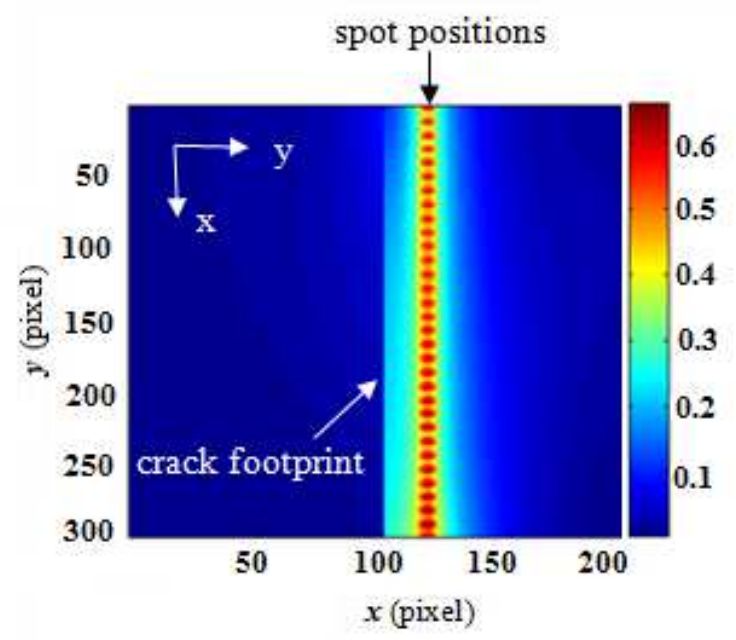

(a)

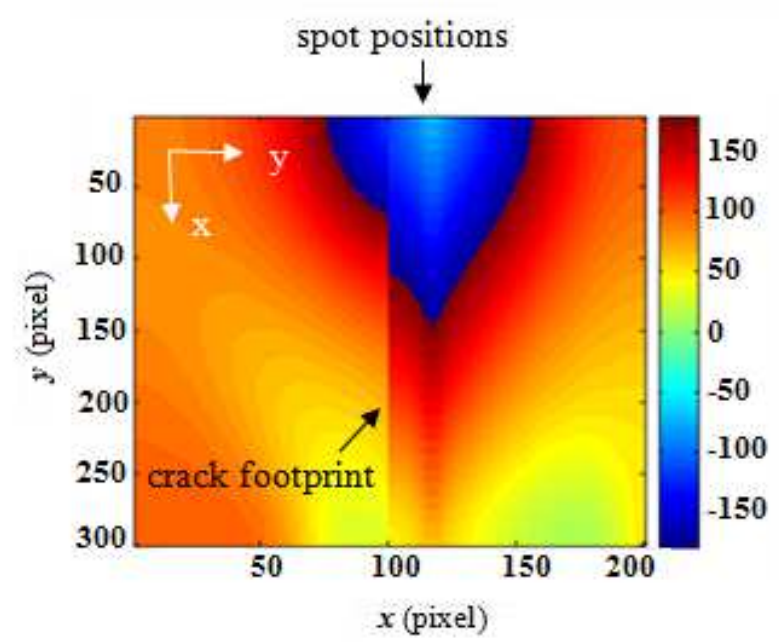

(b)

Figure 5: Calculated temperature images. 1 pixel represents $70 \mu \mathrm{m} \times 70 \mu \mathrm{m} . d=1.25 \mathrm{~mm}$. Depth $h$ range: $0-3$ $\mathrm{mm}$.

(a): amplitude image A (arbitrary units a.u.). (b): raw phase image (degree).

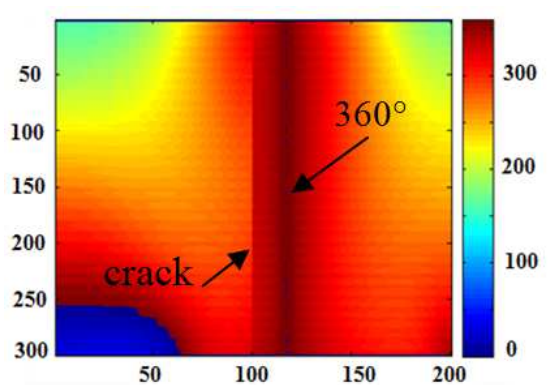

(a)

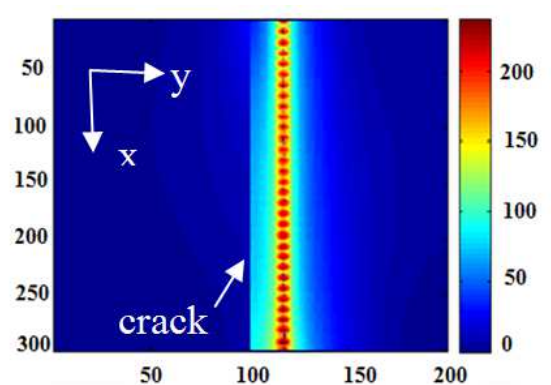

(b)

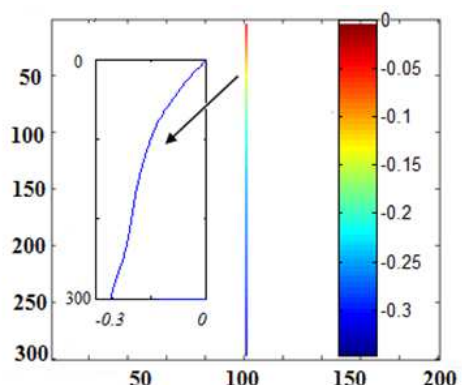

(c)

Figure 6: (a) Shifted phase image $\varphi$ (degree). (b) $A . \varphi$ image (a.u.). (c) Crack footprint $G(x, 101)$ obtained from Figure 6 b for $y=101$ (a.u.).

For each speed $v_{i}$ of the heating spot, an image $\mathrm{G}$ is calculated. To analyze the crack signature of the selected pixels $P(x, y)$, it is proposed to study $G(x, y)^{2}$ normalized by its maximum as a function of the square of the pseudo thermal diffusion length $\mu^{* 2}$. The square function is used to amplify the sensitivity of the method. In the following, $\mu^{* 2}$ is noted $I$.

FEM results are presented in Figure 7 for four constant depths $h$ and for five frequencies between $0.2 \mathrm{~Hz}$ and $2 \mathrm{~Hz}$. The polynomial fits $f_{h}$ of these results show a shift along the $I$ axis which depends on the depth $h$ taken for the simulations. 


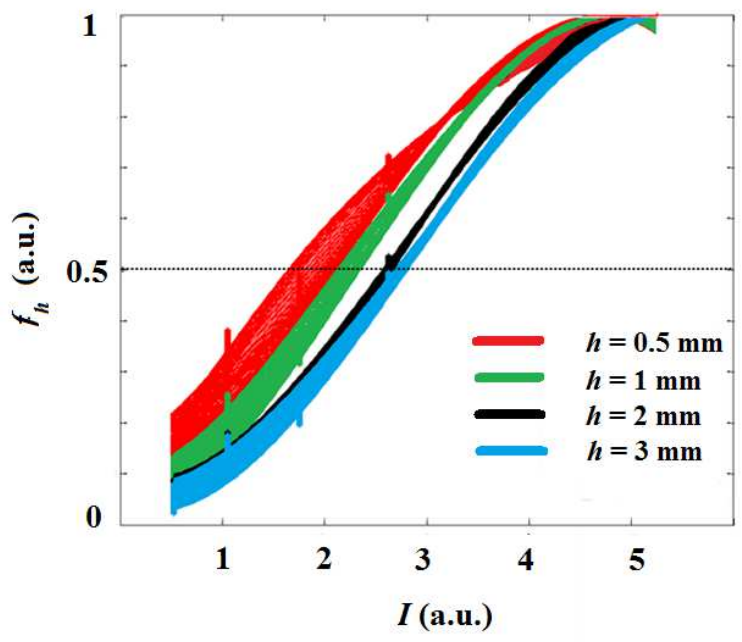

Figure 7: FEM simulation results for 5 frequencies and fits as a function of $I$ for a constant depth $h$ for 300 selected pixels along the crack.

The set of curves obtained for one simulated depth shows that the position of the curves depends on pixel localization too. As in these simulations the scanning distance $d$ between the laser and the crack is constant, the spreading of the responses (important for small $h$ ) is due to the asymmetry of the moving heating spot.

Therefore, the scanning is operated in the two directions, positive $x$ and negative $x$ directions, as illustrated in Figure 8. The values of $I$ corresponding to $f_{h}(I)=0.5$ are reported in Figure 9 for these 2 scanning directions.

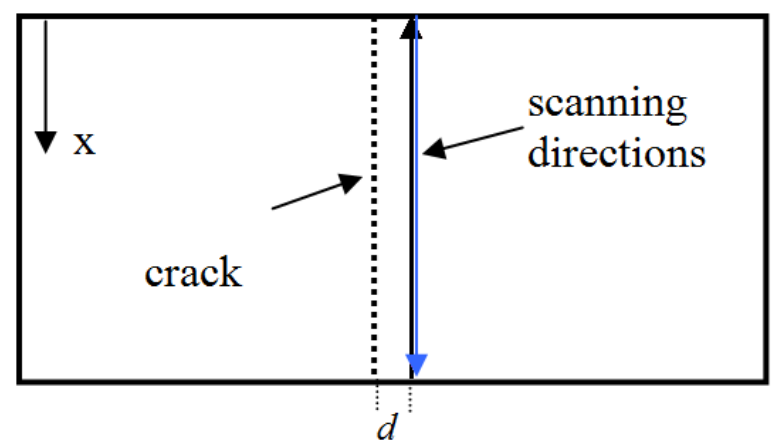

Figure 8: Two scanning directions for a constant distance d.

The superposition of the results shows that the differences induced by the scanning direction along the crack can be reduced by averaging the positive and negative $x$ scans for each pixel. 


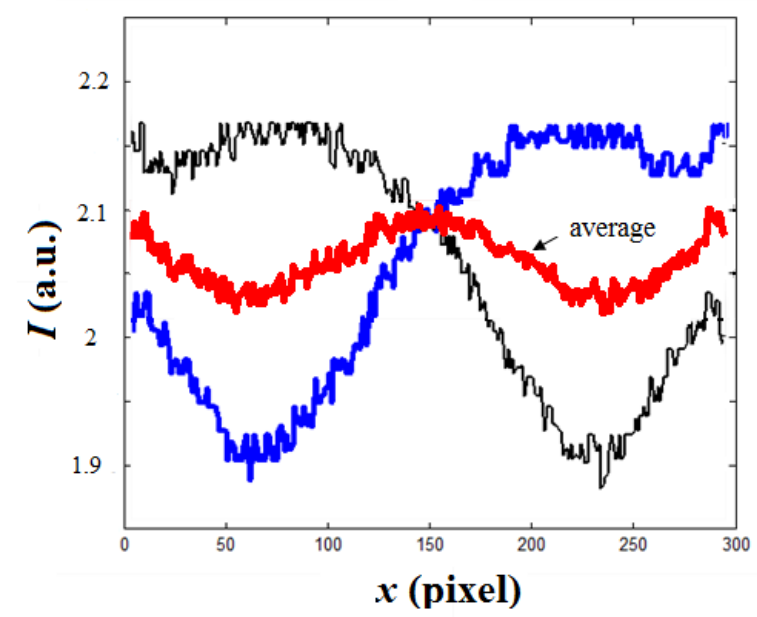

Figure 9: $I(x)$ (a.u.) obtained for a positive and a negative $\mathrm{x}$ scan along a crack with a constant depth. These profiles show the influence of the scanning direction and the interest to average the 2 scans (red curve). 1pixel represents $70 \mu \mathrm{m}$.

\subsection{Depth indicator $I_{d}$}

The values of $I$ are representative of the crack footprint but the $d$ distance between the scanning heating spot and the crack must be taken into account to get access to the quantitative evaluation of a crack depth (Figure 10).

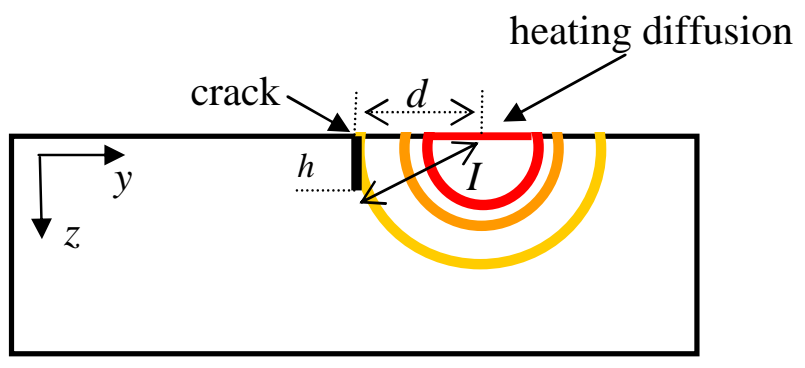

Figure 10: $y, z$ sample model. $\mathrm{d}$ is the crack distance from the center of the heating source. I corresponds to the crack footprint.

An indicator $I_{d}$ of the crack depth can then be deduced using a simple Pythagor relation between $I$ and $d$ :

$$
I_{d}=\sqrt{I^{2}-d^{2}}
$$


To reduce the influence of the scanning direction (see Figure 9), it is preferable to average the $I_{d}$ results obtained from two opposite scanning directions. In Figure 11, $I_{d}$ is averaged on the two opposite scanning directions and is presented for 4 constant depth simulations. A simple transformation function is proposed to evaluate directly and quantitatively the crack depth:

$$
h_{e v}=\exp \frac{I_{d}-b}{a}
$$

where $a$ and $b$ are the coefficients deduced from of the $I_{d}$ fit (Figure 11).

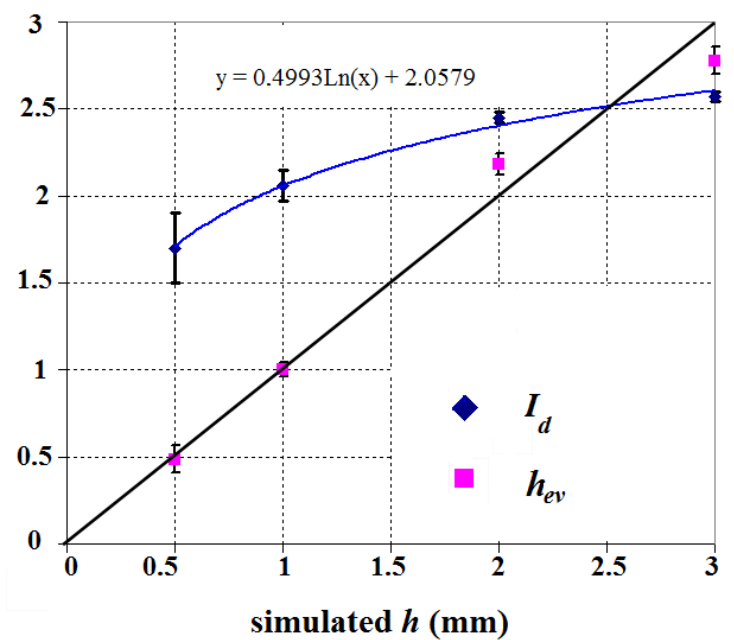

Figure 11: Evaluated depth $h_{e v}(\mathrm{~mm})$ calculated from the transformation function using indicators $I_{d}$ for 4 simulated constant depths. The equation of the Logarithmic fit of the $I_{d}$ values allows to deduce the $a$ and $b$ coefficients of equation (5). $a=0.4993$ and $b=2.0579$.

The transformation function gives a good depth estimation for these simulated results as shown in Figure 11. However, Equation (5) is only well suited for $I$ lower or equal to 5.

Simulations with different thermal diffusions and different maximum $\Delta t$ values show that $I_{d}$ depends linearly on $I_{\max }$ where $I_{\max }=\frac{\alpha \Delta t_{\max }}{\pi} 10^{6}$ is the maximum $I$ value (see Figure 12). Consequently, the expression (5) has to take into account $I_{\max }$ in the definition of the $a$ and $b$ coefficients. 


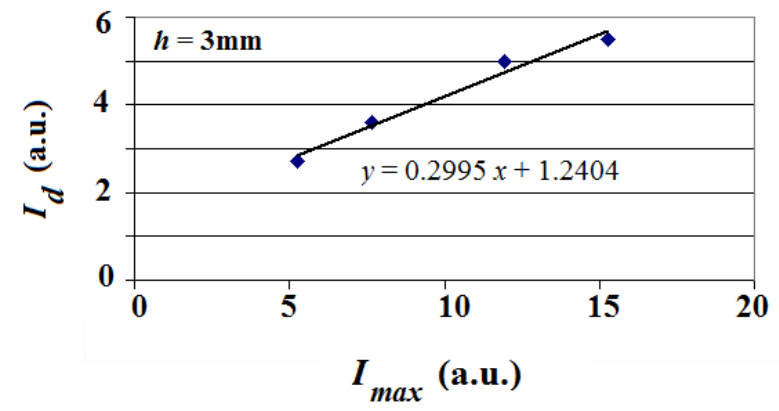

(a)

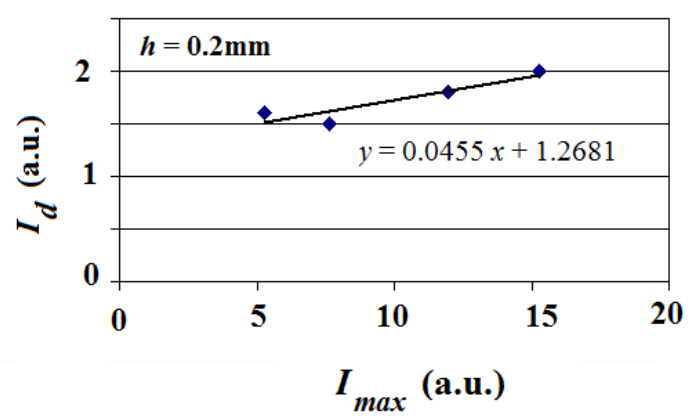

(b)

Figure 12: $I_{d}$ as a function of $I_{\max }$ for two extreme depths $h$. The linear fits allow to obtain the coefficients for the depth evaluation. (a) $h=3 \mathrm{~mm}$. (b) $h=0.2 \mathrm{~mm}$.

Deduced from the simulations with $I_{\max }$ between 5 to 15 , one obtains:

$$
h_{e v}=\exp \frac{I_{d}-b}{a} \text { with } a=0.11 I_{\max } \text { and } b=0.2 I_{\max }+1
$$

\section{6. $\quad$ Crack width independency on depth indicator}

In the real case, crack depth is not constant. In this section, the method is tested for not constant crack depth and for two different crack widths.

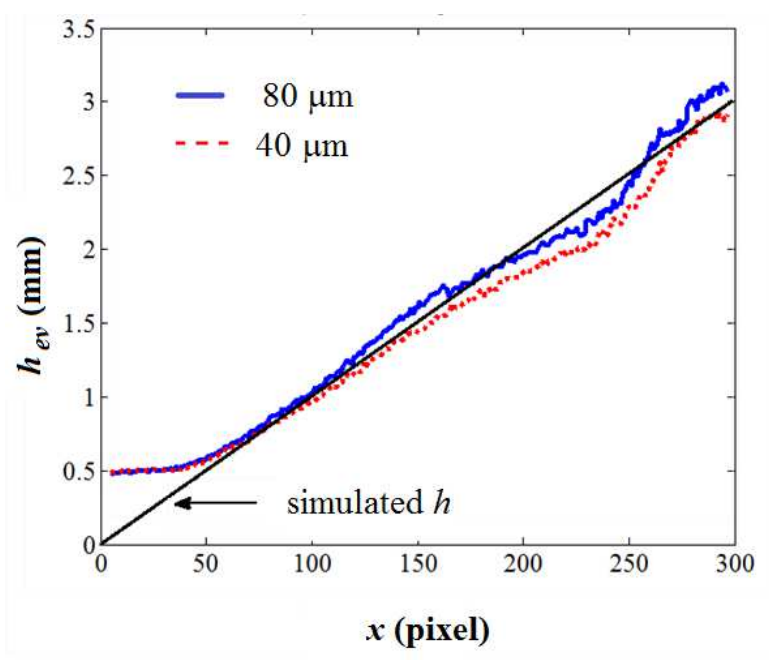

Figure 13: Evaluated depth $h_{e v}(\mathrm{~mm})$ in x direction for non constant crack depth and for two crack widths. The black line corresponds to the simulated depth. $d=1 \mathrm{~mm}$. 1pixel represents $70 \mu \mathrm{m}$.

The crack depth is chosen between 0 and $3 \mathrm{~mm}$ (see Figure 2). The evaluated depth is calculated using Equation (6). Figure 13 shows that $h_{e v}$ is consistent with the simulated depth shape, regardless of the crack width. Indeed, the two crack widths produce almost the same profile for the depth indicator. 
Consequently, the method allows thus to evaluate the crack depth with poor dependency on the crack width.

\section{7. $\quad$ Scan distance independency on averaged depth indicator}

The displacement of the heating source may not be parallel to the crack path. In this section, the crack path on the surface is tilted with respect to the heating source displacement. In this configuration, the scanning distance $d$ between the laser and the crack is not constant and depends on position $x$. The crack depth is also not constant, chosen between 0 and $3 \mathrm{~mm}$. As it is shown in Figure 14, four scanning displacements are considered, 2 (positive and negative scanning) for each side (side 1 and side 2) relative of the crack.

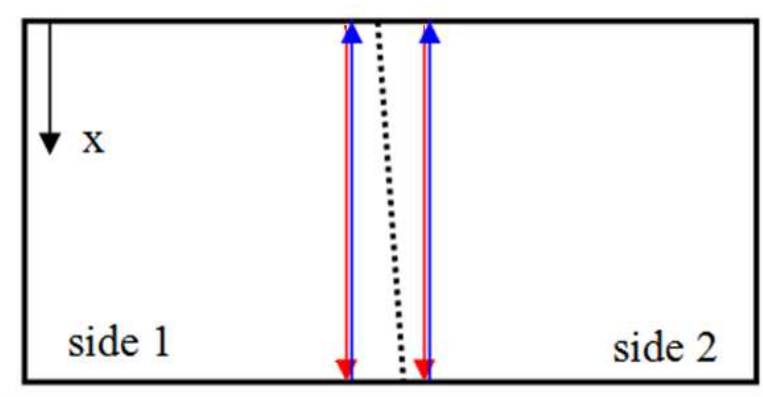

Figure 14: 4 scanning displacements in case of a non-constant distance $d(x)$. The sides are delimited by the crack path on the surface.

Results obtained for the two sides $(s 1$ and $s 2)$ with the two directions ( $\mathrm{x}+$ and $\mathrm{x}$ - direction) are presented in Figure 15. The difference between the two positive scan directions (as between the two negative scan directions) shows that the depth indicator depends on the distance between the heating spot and the crack. So as could be expected, the indicator $I_{d}$ depends on the direction and on the side of the scan. To reduce this dependency, instead of averaging the two scanning directions at one side, it is preferable to average the results of one direction on one side to those of the other direction on the other side. This averaging compensates both for the scanning direction and for the varying distance between the heating source and the crack. The Equation (6) is applied to the averaged $I_{d}$. 


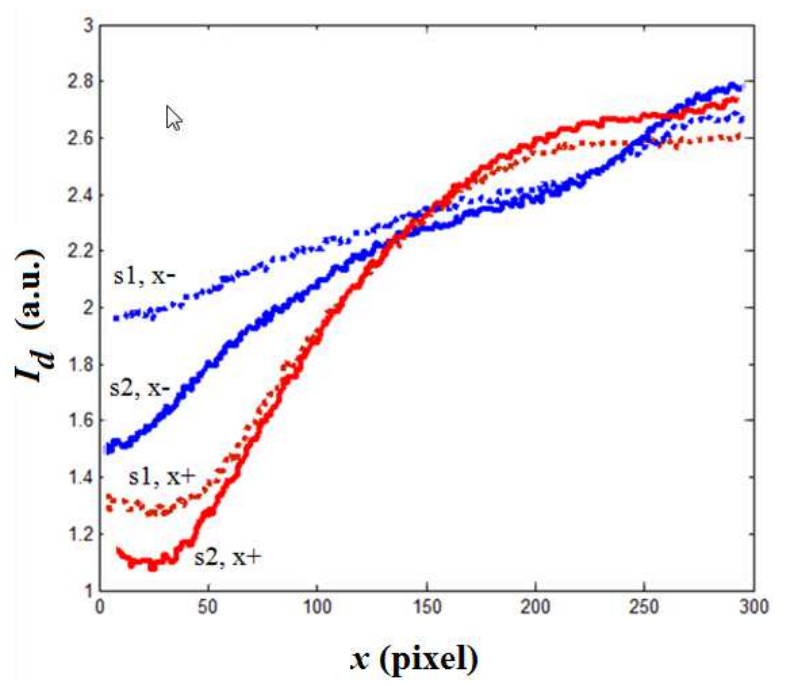

Figure 15: $I_{d}$ along the crack in x direction (1pixel represents $70 \mu \mathrm{m}$ ) for 4 scanning processes (side 1 and side 2 with positive and negative directions. $d(x)$ is varying linearly between $1 \mathrm{~mm}$ and $1.25 \mathrm{~mm}$.

Figure 16 shows the resulting $h_{e v}$ for two averaging possibilities, s1,x- with $\mathrm{s} 2, \mathrm{x}+$ in continuous line and $\mathrm{s} 1, \mathrm{x}+$ with $\mathrm{s} 2, \mathrm{x}$ - in dotted line. As expected, obtained results are clearly improved and are now comparable to the ones with parallel scanning (Figure 13). Therefore, it can be said the resulting $h_{e v}$ are independent on the distance from the spot to the crack.

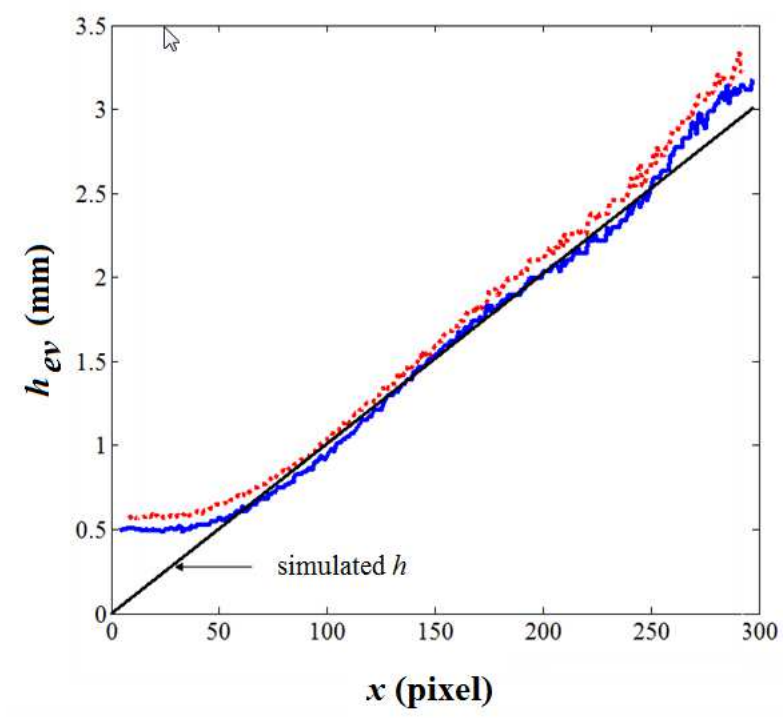

Figure 16: Evaluated averaged depth $h_{e v}(\mathrm{~mm})$ along the crack in $x$ direction ( 1 pixel represents $\left.70 \mu \mathrm{m}\right)$. The continuous line results from the average of $s 1, x$ - and $s 2, x+$ responses. The discontinuous line results from the average of $s 1, x+$ and $s 2, x$ - responses. The black line corresponds to the simulated depths.

\section{Experimental results}

The procedure numerically studied in the previous part is tested on measurements in this section. 


\subsection{Experimental set-up and methodology}

The experimental set-up (see Figure 17) includes a continuous heat source (Ytterbium fiber laser, $1100 \mathrm{~nm}$ wavelength and tuneable power), a scanning galvanometer mirror positioning system and an infra-red camera (Jade III, CEDIP, FLIR). The capture of infra-red images, the displacement of the mirrors and the laser output power are controlled by a NI DAQ module of NI. Figure 18 shows a typical command diagram.

The laser beam is focused onto the surface, near the crack in an approximately uniform and circular spot of $0.5 \mathrm{~mm}$ diameter. No surface preparation has been applied to the studied samples. The laser power is $\mathrm{ON}(2 \mathrm{~W})$ during a controlled $\Delta t$ duration which depends on the length $L$ and speed $v$ of the spot displacement. The laser is OFF when it goes back to its initial position. The spot is displaced by the mean of the rotation of 2 mirrors. The spot scan is controlled from the position command signal of the galvo motors.

The infra-red radiations emitted from the sample surface are measured directly by an infra-red camera. This camera has InSb detectors arranged as $240 \times 320$ pixels and is sensitive in the 3 to $5 \mu \mathrm{m}$ wavelength range. The camera trigger signal is used to synchronize the camera lock-in detection module (FLIR R9902). This synchronous detection module extracts the component from the infrared signal at the different frequencies $f_{i}=v_{i} / L$. The amplitude and phase images of the $f$-component of the infrared emission from the inspected sample surface are then extracted with a fairly good contrast.

The distances $d$ are deduced for each crack selected pixels once the heated area pixels have been located from amplitude images. The gradient of the product of the amplitude and phase images is calculated via a program running under Matlab according to the procedure described in the former section in order to obtain $I$ from the polynomial fits of $G^{2}\left(\mu^{2}\right)$ and then $I_{d}$ from Equation (4). The crack depth is evaluated from Equation (6). Notice that local diffusivity $\alpha$ of each sample can be directly extracted from measurements [26], in a homogeneous area sufficiently far away from the crack. 


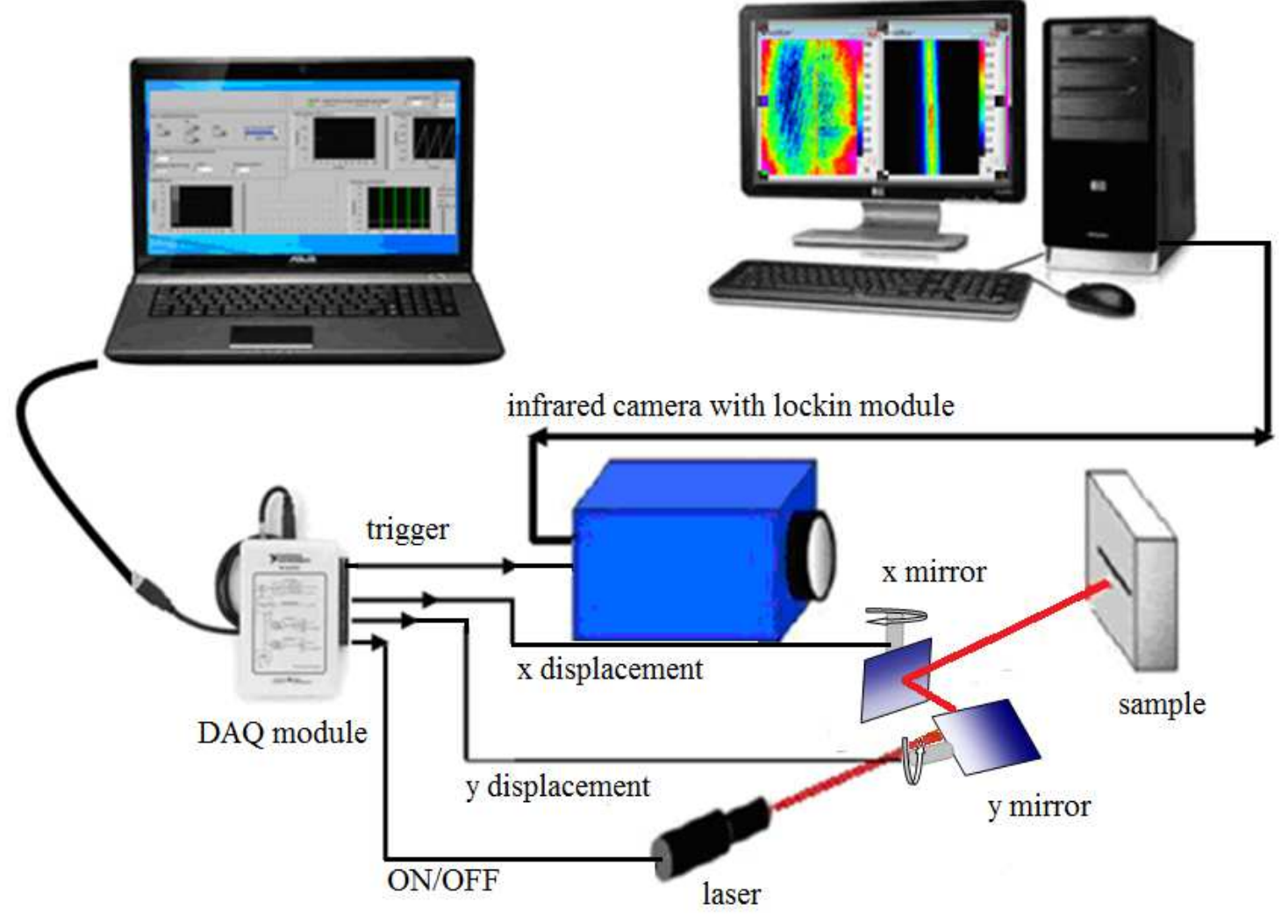

Figure 17: Experimental set-up.

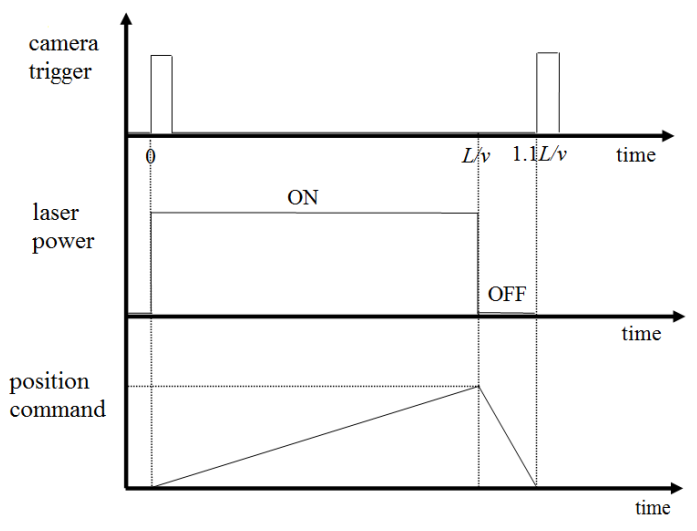

Figure 18: Signals to control the apparatus.

\subsection{Experimental measurements with controlled artificial cracks}

Artificial cracks with a controlled geometry are elaborated to validate experimentally the simulated results presented in the previous sections.

Two $40 \times 40 \times 20 \mathrm{~mm}^{3}$ steel alloy plates separated by $40 \mu \mathrm{m}$ thick brass sheet are assembled with screws to simulate a sample with a vertical open crack. Brass, with its good thermal conductivity, is used instead of steel to compensate partially the thermal contact on both sides. 


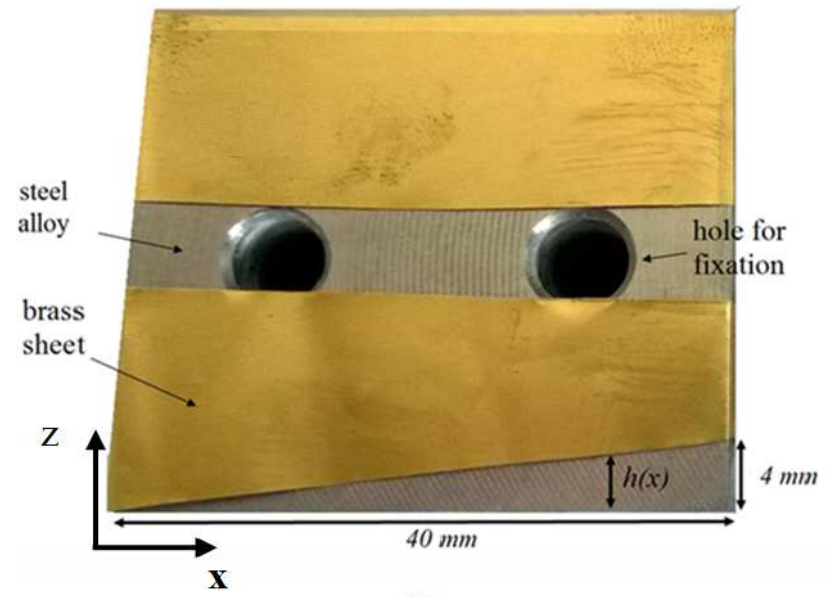

(a)

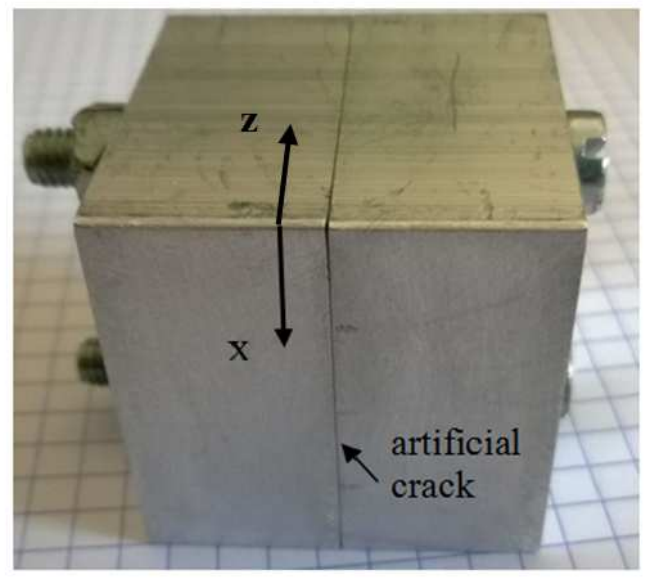

(b)

Figure 19: (a) Photography of the internal structure of an artificial crack. The brass sheets (40- $\mu \mathrm{m}$ thick) are put on steel plate before assembling. (b) Mounted artificial crack with two steel plates screwed together to tightly press the brass spacer in between. An artificial crack with a non constant depth from 0 to $4 \mathrm{~mm}$ is then formed.

The brass sheet is cut in $z$ direction so as to leave an air gap of controlled non constant depth between two steel plates (Figure 19b). Two samples are studied (Figure 20): sample F with $h$ between $1 \mathrm{~mm}$ and $3 \mathrm{~mm}$ and sample $\mathrm{G}$ with $h$ between $0 \mathrm{~mm}$ and $2 \mathrm{~mm}$. The measured thermal diffusivity of the plate is equal to $4.5 \pm 0.3 .10^{-6} \mathrm{~m}^{2} \mathrm{~s}^{-1}$. The duration of the heat source ON/OFF cycle is between 0.5 $\mathrm{s}$ and $8 \mathrm{~s}$.
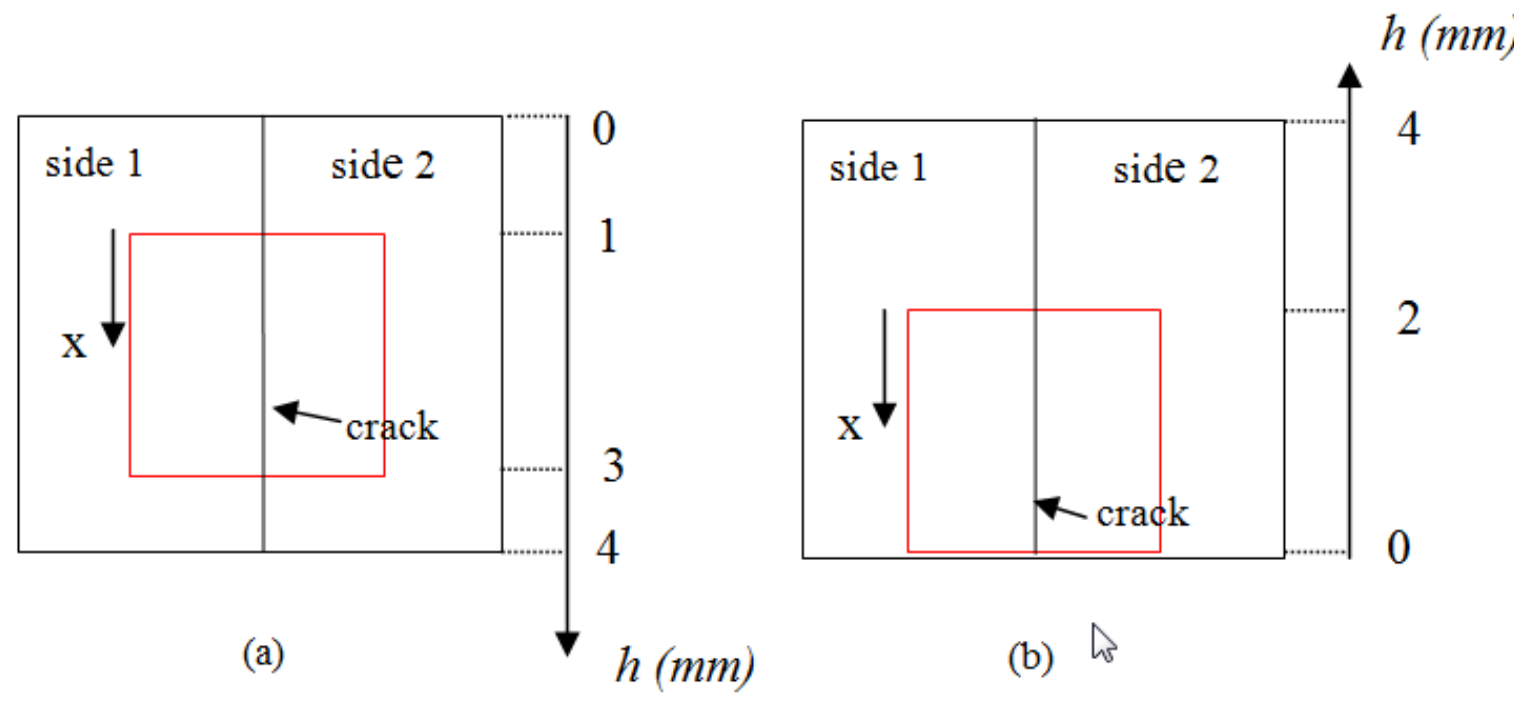

Figure 20: The red squares correspond to the surface area seen by the infrared camera. (a) sample F: $h$ between 1 $\mathrm{mm}$ and $3 \mathrm{~mm}$, (b) sample G: $h$ between $2 \mathrm{~mm}$ and $0 \mathrm{~mm}$. 


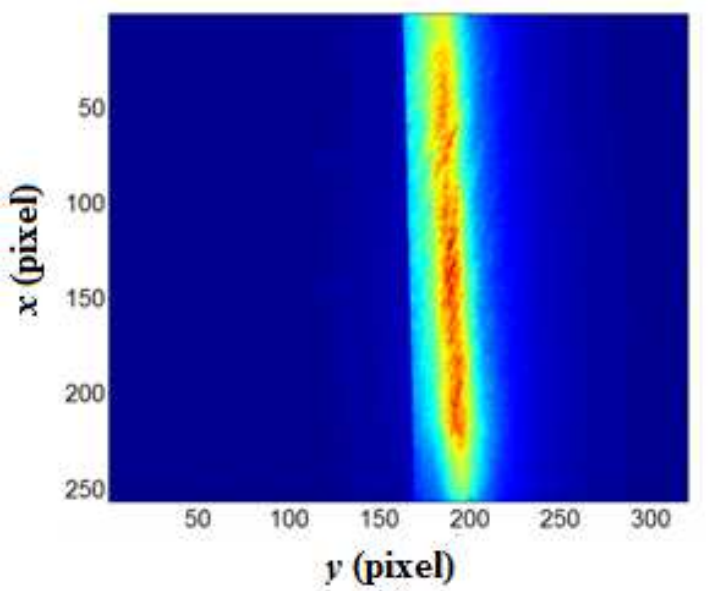

(a)

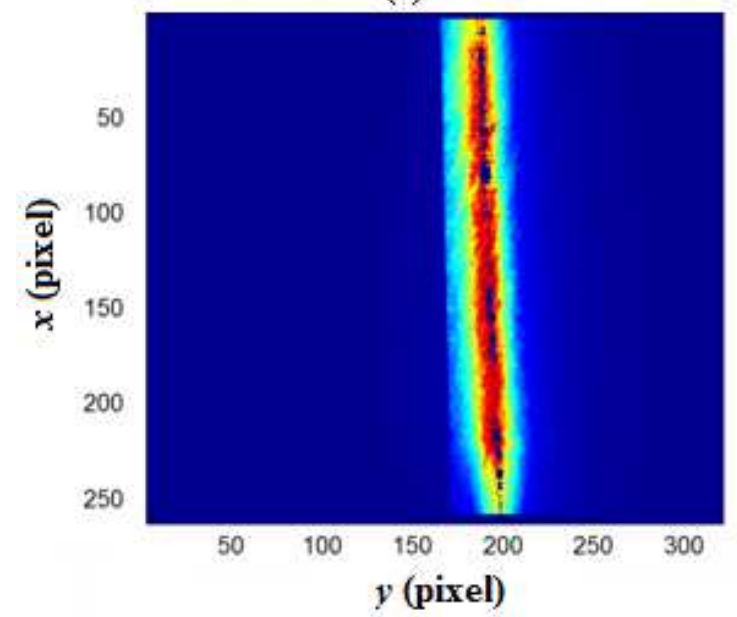

(c)

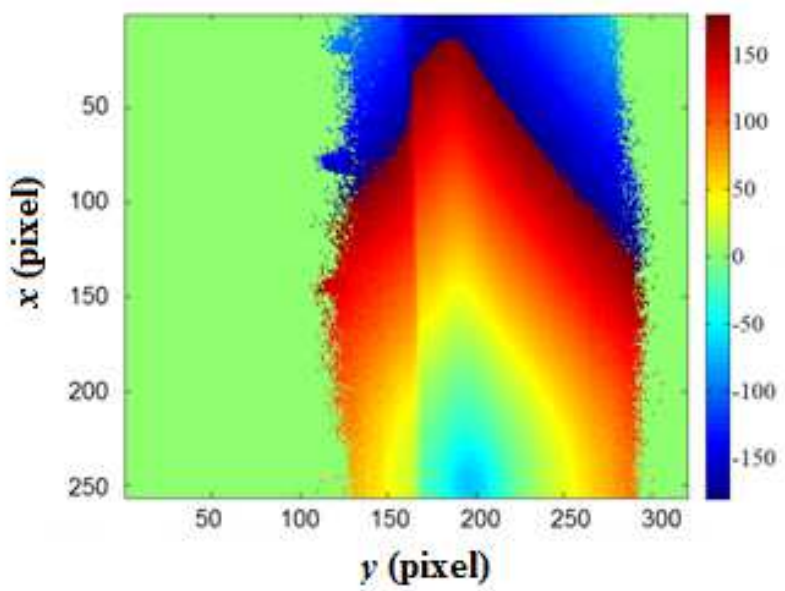

(b)

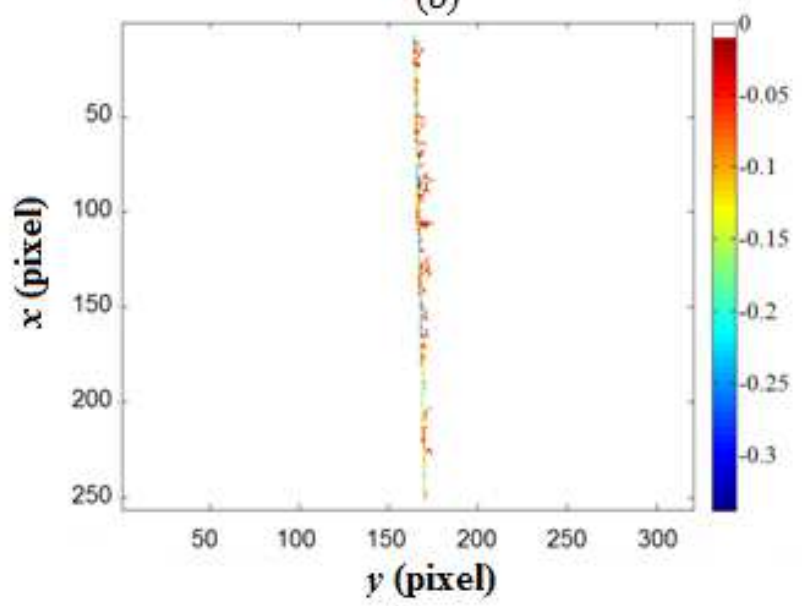

(d)

Figure 21: Infrared images. 1 pixel represents $78 \mu \mathrm{m} \times 78 \mu \mathrm{m}$. (sample $\mathrm{G}$, laser on side 2, spot displacement for negative $x, \Delta t=5 \mathrm{~s}$ ). (a): amplitude image (a.u.). (b) raw phase image (degree). (c) A. $\varphi$ image (a.u.). (d) obtained crack footprint (a.u.).

Figures 21a and 21b show an example of the measured amplitude and phase infrared images obtained for sample $\mathrm{G}$ with the laser spot positioned on side 2 and moving toward negative direction. Figure $21 \mathrm{~d}$ represents the crack footprint of sample $\mathrm{G}$ calculated from the gradient of the product of amplitude and phase images (Figure 21c). The amplitude and phase images of $5 f$-components are analyzed on each side (side 1 and side 2) of the crack and for each direction (positive and negative).

The measured local distances $d(x)$ between laser and crack, reported in Figure 22, show that $d(x)$ varies between $1 \mathrm{~mm}$ and $1.5 \mathrm{~mm}$. As discussed in section 2.7, these variations have to be taken into account in the depth estimation 


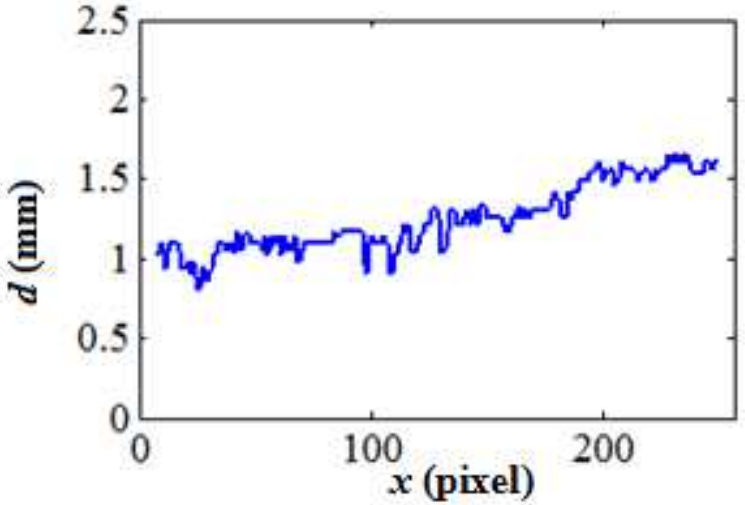

(a)

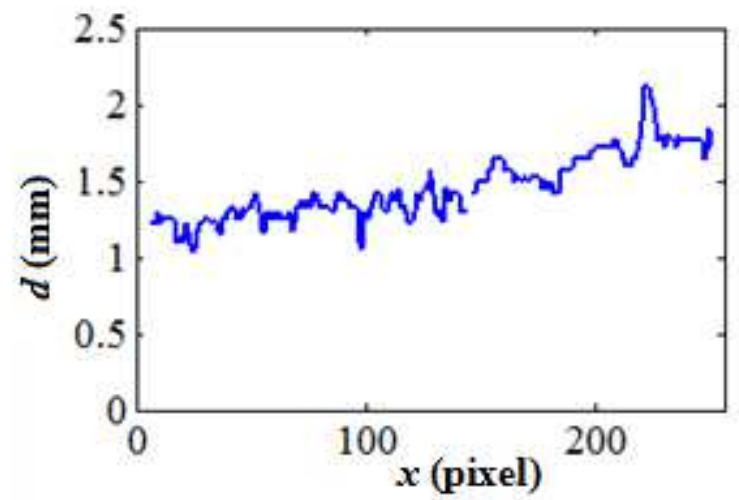

(c)

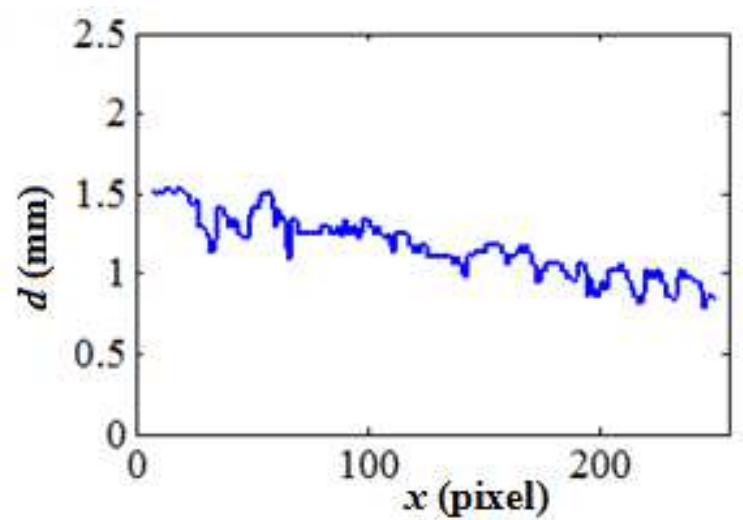

(b)

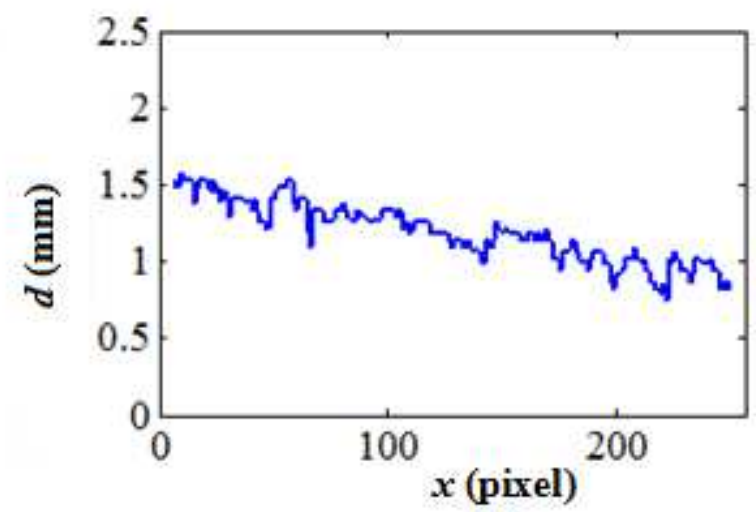

(d)

Figure 22: Laser position $d(x)$ along the crack for the 4 scans (sample G, scanning distance : 20 mm, 1 pixel represents $78 \mu \mathrm{m}$ ). (a) side 2 , negative displacement. (b) side 1 , negative displacement. (c) side 2, positive displacement. (d) side 1, positive displacement.

Figure 23 shows that $I_{d}$ deduced from the selected pixel data of the 4 scans are between 5 and 5.6 for the 1 to $3 \mathrm{~mm}$ crack depth. These values (green triangles) are higher than those expected in "real" crack simulations (blue diamonds), mostly for little crack depth.

As the artificial crack presents a non perfect thermal contact under the crack (steel in dry contact with brass, in dry contact with steel), new simulations (pink squares in Figure 23) are made with the introduction of a $4 \mu \mathrm{m}$ air gap between the $40 \mu \mathrm{m}$ brass sheet and the steel plate, so that they are more representative to the experimental artificial crack geometry. It is worth noting that the impact of the air gap is more important when the crack depth is smaller. Figure 23b shows that the $I_{d}$ calculated for the artificial crack simulations (pink squares) are in better agreement with the $I_{d}$ obtained from the experimental results (green triangles). 


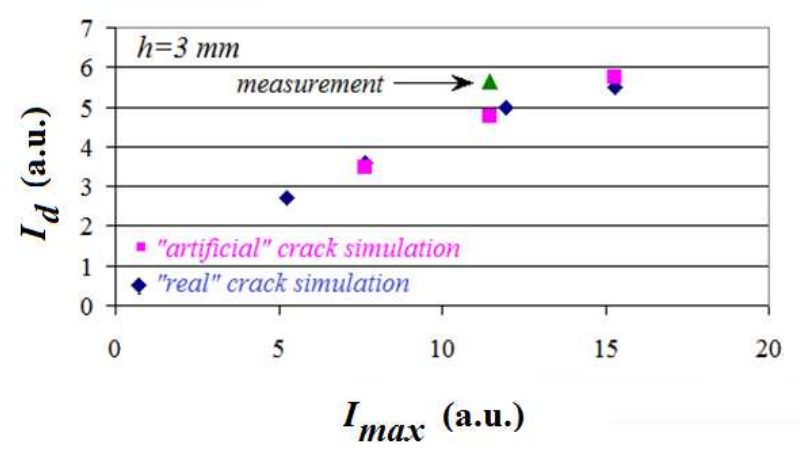

(a)

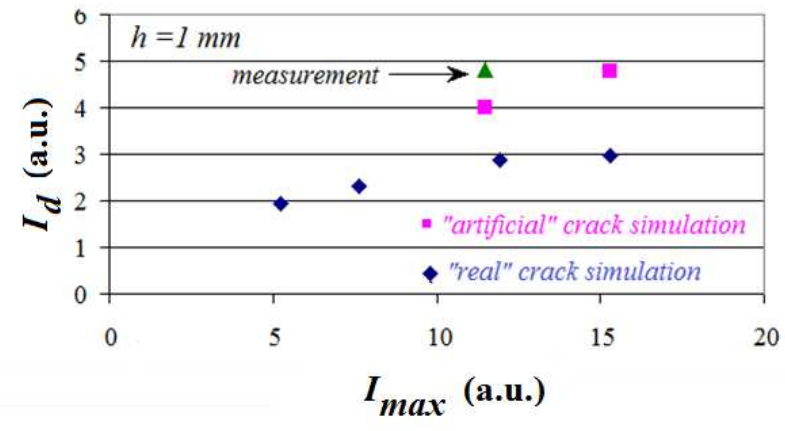

(b)

Figure 23: $I_{d}$ as a function of $I_{\max }$ for two extreme depth $h$ values. The measurement (green triangles) has to be compared to the "artificial" crack simulation (pink square) in which a $4 \mu \mathrm{m}$ air gap is introduced between a $40 \mu \mathrm{m}$ brass sheet and the steel plate, similarly to experimental sample. (a) $h=3 \mathrm{~mm}$; (b) $h=1 \mathrm{~mm}$.

Consequently, $a$ and $b$ expressions of Equation (6) are no longer valid to evaluate the depth for such artificial cracks: the bad thermal contact due to the little air gap between the brass sheet and the steel plate leads to a bias in the determination of the crack depth. Indeed the poorer thermal contact is similar to a deeper effective crack, the expressions of Equation (6) for $a$ and $b$ should be only used for real cracks.

Figure 23b obtained for $h=1 \mathrm{~mm}$ shows that $b$ coefficient for an artificial crack should be larger than for a real crack. In Figure 24, the local crack depth evaluations (in blue) are deduced along the sample crack using Equation (5) with $a=0.55$ and $b=5$. These results are comparable to the expected depth values (black line).

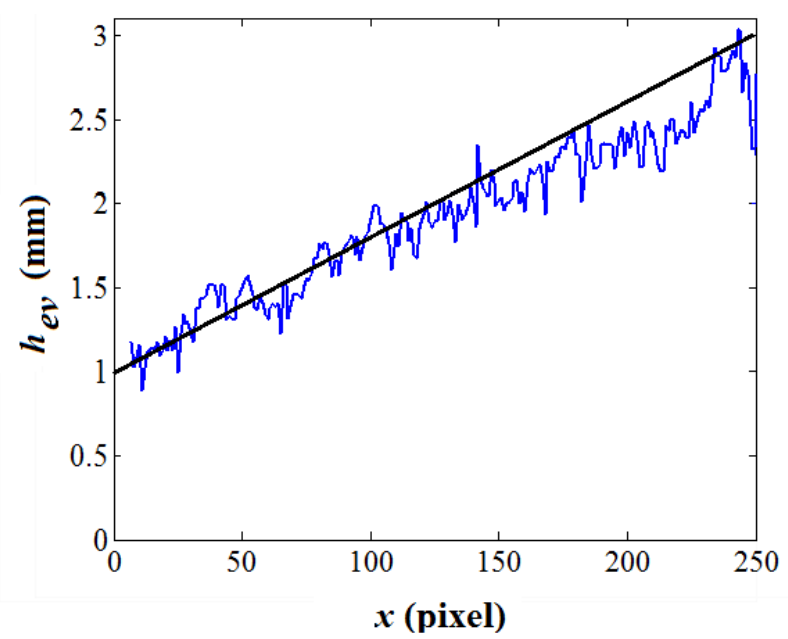

(a)

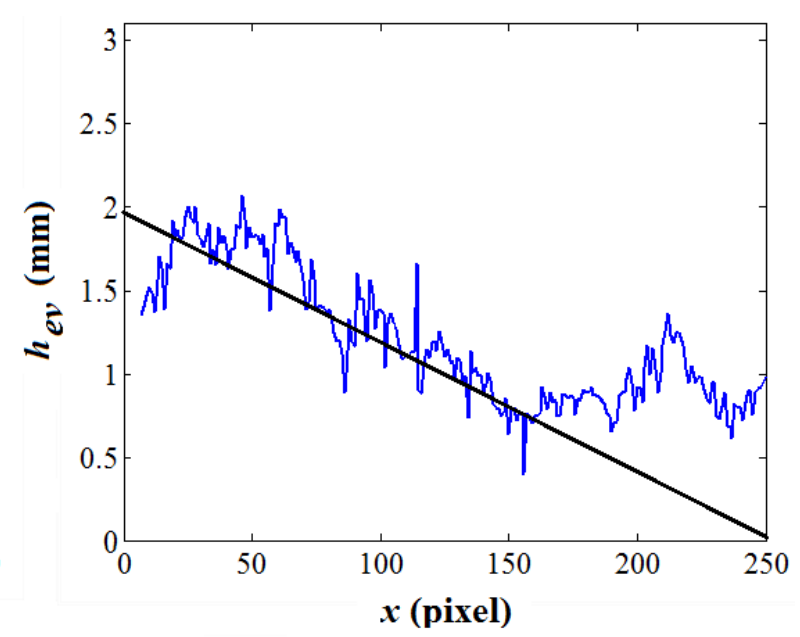

(b)

Figure 24: Evaluation of the local depth $h_{e v}(x)$ along the crack (scanning area: $20 \mathrm{~mm}, 1$ pixel represents $78 \mu \mathrm{m}$ ) using Equation (5) with $a=0.55$ and $b=5$. The black line corresponds to the expected depth values. (a) sample F, (b) sample G 
The experimental results obtained for artificial cracks show that the method well estimates the crack depth.

\subsection{Experimental measurements with induced fatigue cracks}

An open vertical fatigue crack of 35 width in a highly reflecting $130 \times 27 \times 9 \mathrm{~mm}^{3}$ Inconel plate is enforced to form by exerting pressure on 2 extremities of the sample over its entire width. Depths are measured on the 2 lateral sides of the sample using optical microscopy [21] (Table 2). The measured thermal diffusivity of the Inconel sample is $3.3 \pm 0.1 .10^{-6} \mathrm{~m}^{2} \mathrm{~s}^{-1}$. The amplitude and phase images of 5 $f$-components are analyzed on each side of the crack and for each direction as described previously. The duration of the heat source round trip $\Delta \mathrm{t}$ is between $0.5 \mathrm{~s}$ and $8 \mathrm{~s}$ and the laser power is $2 \mathrm{~W}$.

Table 2 Crack sizes of Inconel alloy sample

\begin{tabular}{|l|c|c|c|}
\hline Sample & \multicolumn{2}{|l|}{$\begin{array}{l}\text { Depth (mm) on the two lateral } \\
\text { sides of the sample }\end{array}$} & $\begin{array}{l}\text { crack width } \\
(\mu \mathrm{m})\end{array}$ \\
\hline Inconel & $1 \pm 0.1$ & $3 \pm 0.1$ & $35 \pm 5$ \\
\hline
\end{tabular}

The local depth evaluation along the sample crack is deduced using Equation (6) with $I_{\max }=5.25$ which leads to $a=0.58$ and $b=2.05$. Figure 25 shows that the depth evaluation of the Inconel sample is compatible with the expected lateral depth values (black line on both sides) which allows to deduce that equation (6) seems well suited to evaluate fatigue crack depths.

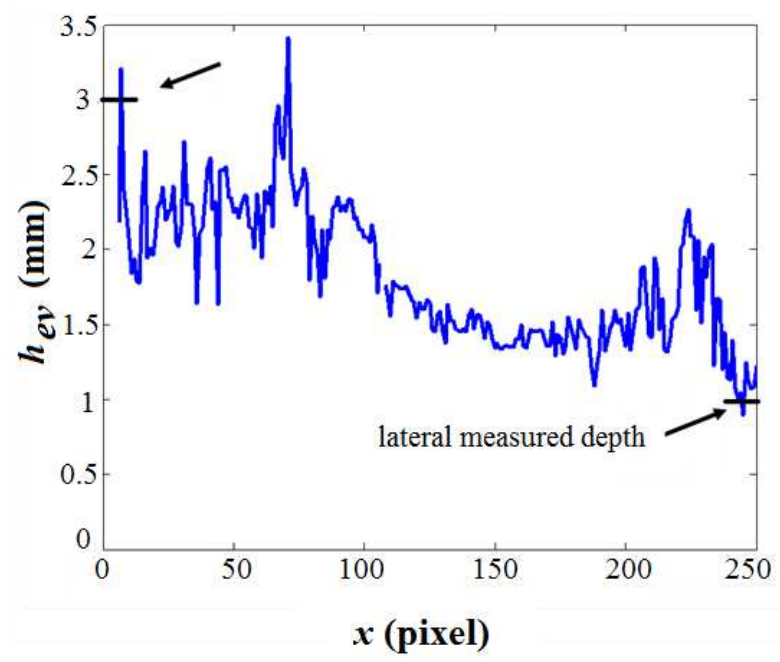


Figure 25: Evaluation of the local depth $h_{e v}(x)$ along the crack of the Inconel sample (scanning area: $9 \mathrm{~mm}, 1$ pixel represents $40 \mu \mathrm{m})$ using equation $(6)$ with $I_{\max }=5.25(a=0.58 . b=2.05)$. The black lines correspond to the expected lateral depth values.

\section{Conclusion}

In this work, an original method to evaluate the depth of few centimetre long crack is presented. The surface of the material does not require to be prepared for implementing the method. A continuous heating spot moves along the crack at different speeds in order to heat more or less deeply the sample. The different speeds for the displacement of the heating source have to be correctly chosen, depending of the thermal diffusivity of the studied material. Infrared images are acquired using a lock-in detection system, synchronised with the spot movement. The multi-speed lock-in thermography approach has been first studied with simulations. Two crossing scans are analysed to reduce the influence of the non-symmetric heating area due to the moving heating spot. Measurements on controlled artificial cracks have experimentally validated the method for depths less than $3 \mathrm{~mm}$. 2-W lasers are sufficient to scan length around $20 \mathrm{~mm}$. Once the spot is correctly positioned near the crack, the total acquisition duration corresponds to the sum of the heat source ON/OFF cycle durations per scans if there is no average during lock-in procedure. For the presented study, the total acquisition duration is around 4 minutes: one minute for each scan of 5 different ON/OFF cycles with 4 times lock-in averaging and 4 scans. The acquisition time is of the same order as with the multi-frequency lock-in infrared thermography method. However, the described multi-speed continuous heating source associated with a lock-in detection allows to evaluate cracks of a few centimetres long while the previous multi-frequency lock-in infrared thermography method could only evaluate cracks of a few millimetres long. For testing longer cracks with the same cycle duration, that is to say with the same pseudo thermal diffusion lengths, the laser displacement speeds must be increased. Therefore the power of the laser should be increased accordingly to heat more rapidly the surface sample. 
[1] U. Netzelmann, Flying-spot lock-in thermography and its application to thickness measurement and crack detection, QIRT14, DOI: 10.21611/qirt.2014.064

[2] M. Piriou, C. Moreau, M. P. Leyris, the photothermal camera method technology update and recent results, 10th ECNDT moscow, june 7-11 (2010)

[3] J.-C. Krapez, L. Legrandjacques, F. Lepoutre, D. L. Balageas, optimization of photothermal camera for crack detection, QIRT open archives, Proc. 4th QIRT, Lodz Poland, 1998, p 48, DOI: 10.21611/qirt.1998.048

[4] Chiwu Bu, Qingju Tang, Yuanlin Liu, Xiangyang Jin, Zhihui Sun, Zugen Yan, A theoretical study on vertical finite cracks detection using pulsed laser spot thermography (PLST), Infrared Physics \& Technology Vol 71, July 2015, Pages 475-480, DOI : 10.1016/j.infrared.2015.05.009

[5] N. W. Pech-May, A. Oleaga, - A. Mendioroz, - A. Salazar, Fast Characterization of the Width of Vertical Cracks Using Pulsed Laser Spot Infrared Thermography, J Nondestruct Eval (2016) 35:22 DOI 10.1007/s10921-016-0344-x

[6] J. Schlichting, Ch. Maierhofer and M. Kreutzbruck, Crack sizing by laser excited thermography, NDT\&E Int. 45, 133-140, 2012

[7] O. Wysocka-Fotek, W. Oliferuk, M. Maj, Reconstruction of size and depth of simulated defects in austenitic steel plate using pulsed infrared thermography, Infrared Physics \& Technology 55 363-367, 2012

[8] Li T, Almond D P and Rees D A S, crack imaging by scanning pulsed laser spot therrmography, 2011 NDT\&E Int. 44 216-25

[9] R. Celorrio, A J Omella, N W Pech-May, A Oleaga, A Mendioroz, A Salazar, Vertical cracks characterization using lock-in thermography: II finite cracks, Meas. Sci. Technol. 25 (2014) 115602 (9pp), doi:10.1088/0957-0233/25/11/115602

[10] C. Wallbrink, S. A. Wade, and R. Jones, The effect of size on the quantitative estimation of defect depth in steel structures using lock-in thermography, J. Appl. Phys. 101, 104907 (2007); doi: $10.1063 / 1.2732443$

[11] N W Pech-May, A Oleaga, A Mendioroz, A J Omella, R Celorrio, A Salazar, Vertical cracks characterization using lock-in thermography: I infinite cracks, Meas. Sci. Technol. 25 (2014) 115601 (10pp) doi:10.1088/0957-0233/25/11/115601

[12] Lugin S., detection of hidden defects by lateral thermal flows, NDT\&E Int. 56 48-55 (2013)

[13] Li T, Almond D., P Rees D. A. S., crack imaging by scanning laser-line thermography and laser-spot thermography, 2011 Meas. Sci. Technol., 22(3) 035701

[14] P. Myrach, M. Ziegler, C. Maierhofer, M. Kreutzbruck, Influence of the acquisition parameters on the performance of laser-thermography for crack detection in metallic components, AIP Conference Proceedings 1581, 1624 (2014); doi: 10.1063/1.4865018

[15] R. Celorrio, A. J. Omella, Finite element model for crack characterization by lock-in thermography, QIRT 108, 2014

[16] R. Celorrio, A. J. Omella, A. Mendioroz, A. Oleaga, · A. Salazar, Advances in Crack Characterization by Lock-In Infrared Thermography, Int J Thermophys (2015) 36:1202-1207, DOI 10.1007/s10765-014-1676-3

[17] L. Gavérina, JC Batsale, C. Pradere, D. Mourand, Several considerations about a pulsed flying spot method implemented with IR thermography, QIRT 30, 2015,DOI: 10.21611/qirt.2015.0030

[18] S. Beuve, Z. Qin, J.-P. Roger, S. Holé, C. Boué, Open cracks depth sizing by multi-frequency laser stimulated lock-in thermography combined with image processing, Sensors and Actuators A 247 (2016) 494-503, DOI : 10.1016/j.sna.2016.06.028 
[19] C. Boué, G. Tessier, J.-P. Roger, M. Streza, Method for assessing the depth of a crack, US Patent, publication number 2015-0241212, 2015

[20] C. Boué, G. Tessier, J.-P. Roger, M. Streza, Procédé d'évaluation de la profondeur d'une fissure French Patent Application n ${ }^{\circ} 12$ 58940, PCT/FR2013/052185, CNRS - UPMC, 2013

[21] Y. Fedala, M. Streza, J.-P. Roger, G. Tessier, C. Boué, Open cracks depth sizing by laser stimulated Infrared lock-in thermography, J. Phys. D: Appl. Phys. 47, 465501 (6pp), 2014

[22] M. Streza, Y. Fedala, J.-P. Roger, G. Tessier, C. Boué, Heat transfer modeling for surface crack depth evaluation, Meas. Sci. Technol. 24, 045602 (6pp), 2013

[23] https://www.comsol.fr/

[24] H.S. Carslaw, J.C. Jaeger, Conduction of Heat in Solids, $2^{\text {nd }}$ ed, Oxford Press, 1959. p.16

[25] Y. Fedala, M. Streza, F. Sepulveda, J.-P. Roger, G. Tessier, C. Boué, Infrared lock-in thermography crack localization on metallic surfaces for industrial diagnosis, Journal of Non Destructive Evaluation, DOI 10.1007/s10921-013-0218-4, 2013

[26] C. Boué , S. Holé, Infrared thermography protocol for simple measurements of thermal diffusivity and conductivity, Infrared Phys. Tech. 55 376-79, 2012 